\title{
Abundância de ramos reprodutivos e produção de sementes em populações de Ipomoea pes-caprae (L.) R. Br. na Ilha de Santa Catarina, Brasil
}

\author{
Tânia Tarabini Castellani ${ }^{1,2,4}$ e Flavio Antonio Maës dos Santos ${ }^{3}$
}

Recebido em 15/08/2003. Aceito em 03/09/2004

RESUMO - (Abundância de ramos reprodutivos e produção de sementes em populações de Ipomoea pes-caprae (L.) R. Br. na Ilha de Santa Catarina, Brasil). As variações na proporção de ramos reprodutivos e na produção de frutos e sementes de Ipomoea pes-caprae (L.) R. Br. (Convolvulaceae) foram avaliadas em dez praias da Ilha de Santa Catarina, SC, Brasil. Três manchas por praia foram monitoradas, envolvendo dois ciclos reprodutivos. Ipomoea pes-caprae apresentou manchas com extensões médias iniciais de $14 \mathrm{~m}$, com cerca de 9,6 ramos $/ \mathrm{m}^{2}$ e $39 \%$ de ramos reprodutivos. A proporção de ramos reprodutivos variou entre os ciclos, não se observando alternância de esforço reprodutivo entre os ciclos subseqüentes. Houve redução da percentagem de ramos reprodutivos em seis localidades. Em quatro praias onde houve redução populacional de Ipomoea pes-caprae, ocorreu redução de vigor reprodutivo e da produção de sementes, sendo estes declínios associados à forte erosão marinha. Por outro lado, em uma praia onde houve crescimento populacional, ocorreram poucos ramos reprodutivos, o que foi associado à maior presença de estolões jovens. Não ocorreu amadurecimeto de frutos em quatro manchas, estando três destas em praias pequenas. A produção de frutos nas manchas atingiu valores de 40 frutos $/ \mathrm{m}^{2}$ e $140 \mathrm{sementes} / \mathrm{m}^{2}$. As populações com maior produção de sementes localizaram-se em áreas adjacentes a amplas planícies costeiras, podendo representar fontes potenciais de sementes para as áreas de baixa produção na ilha.

Palavras-chave: duna frontal e praia, ecologia populacional, Ipomoea pes-caprae, floração, produção de sementes

\begin{abstract}
Reproductive branches, abundance, and seed production of Ipomoea pes-caprae (L.) R. Br. on Santa Catarina Island, Brazil). The variation in the proportion of reproductive branches, fruit, and seed production of Ipomoea pes-caprae (L.) R. Br. (Convolvulaceae) were evaluated at ten beaches on Santa Catarina Island, state of Santa Catarina, Brazil. Three patches per beach of Ipomoea pes-caprae were monitored, involving two reproductive cycles. Ipomoea pes-caprae presented initially an average length of patches of $14 \mathrm{~m}$, with 9.6 branches $/ \mathrm{m}^{2}$ and $39 \%$ of reproductive branches. The proportion of reproductive branches varied between the cycles, but there was not noticed an alternation of reproductive effort between the subsequent cycles. There was a reduction in the percentage of reproductive branches at six localities. In four beaches where Ipomoea pes-caprae populations declined, occurred reduction in the reproductive vigor, and in the seed production, being these declines associated to strong sea erosion. In another hand, in one beach with population increase, there were little reproductive branches due to the occurrence of young stolons. Four patches never maturated fruits, being three of these located at small beaches. The fruit and seed productions in the patches showed values up to 40 fruits $/ \mathrm{m}^{2}$ and up to 140 seeds $/ \mathrm{m}^{2}$, respectively. Populations with great seed production were localized in areas adjacent to great coastal plains, which may represent potential seed sources for areas with small seed production in the island.
\end{abstract}

Key words: beach and sand dune, population ecology, Ipomoea pes-caprae, flowering, seed production

\section{Introdução}

A proporção de indivíduos que se reproduzem em uma população de plantas, assim como suas fecundidades, pode variar em função da oferta de recursos e da densidade de indivíduos, bem como de fatores intrínsecos de ordem genética e ontogenética e do próprio esforço reprodutivo em ciclos subseqüentes (Harper 1977; Watkinson 1997; Mantovani \& Morellato 2000).

As plantas de pós-praia e duna frontal são, na maioria, espécies perenes com crescimento clonal (Cordazzo \& Seeliger 2003). Nestas plantas, a discussão sobre a ocorrência de ramos reprodutivos e a fecundidade nas populações tem se relacionado ao dinamismo dos hábitats e/ou às fases de desenvolvi-

\footnotetext{
1 Universidade Federal de Santa Catarina, Centro de Ciências Biológicas, Departamento de Ecologia e Zoologia, C. Postal 476, CEP 88040-900, Florianópolis, SC, Brasil

2 Programa de Pós Graduação em Ecologia, Instituto de Biologia, Unicamp (Bolsista PICD-CAPES)

3 Universidade Estadual de Campinas, Instituto de Biologia, Departamento de Botânica, C. Postal 6109, CEP 13083-970, Campinas, SP, Brasil (Bolsa de produtividade CNPq)

4 Autor para correspondência: ttcastel@ccb.ufsc.br
} 
mento dos clones. Algumas populações mostram redução da densidade de ramos e do vigor reprodutivo, à medida que as dunas tornam-se mais estáveis, do mar ao interior (Pfadenhauer 1978; Huiskes \& Harper 1979; Maun 1985; Costa et al. 1991; Little \& Maun 1996). No entanto, baixa proporção de ramos reprodutivos pode ser registrada em populações em fase invasora em substratos móveis (Costa et al. 1991) e em populações em áreas instáveis, ocorrendo maior alocação de energia à propagação vegetativa (Cordazzo \& Seeliger 2003).

Diferenças no vigor reprodutivo entre populações de plantas de pós-praia e duna frontal são também associadas à dinâmica da linha de costa. Há referências à menor proporção de ramos floridos em praias em progressão, devido à maior produção de ramos jovens, não reprodutivos (Devall et al. 1991; Devall 1992).

No que se refere à dinâmica da linha de costa, a Ilha de Santa Catarina vem evidenciando tendência de regressão em algumas praias do litoral norte e leste (Almeida et al. 1991; Abreu de Castilhos \& Gré 1997; Cruz 1998; Leal et al. 1998), enquanto outras permanecem estáveis desde a década de 1950 (Abreu de Castilhos \& Gré 1997). Monitoramentos de perfis de praia e duna frontal foram realizados em dez praias da Ilha de Santa Catarina de 1996 a 1997 e registraram acentuada erosão no outono-inverno de 1996. No prazo de um ano, 67\% dos perfis estavam mais escavados, sem haver a reconstrução de hábitats destruídos em algumas localidades (T.T. Castellani, dados não publicados).

Ipomoea pes-caprae é uma espécie que coloniza o pós-praia e a duna frontal (Hueck 1955; Wilson 1977; Devall \& Thien 1989). Desta forma, os ciclos naturais de erosão e de acresção de praia (Hesp 2000) podem interferir na abundância e, possivelmente, na reprodução desta espécie. Das populações de Ipomoea pes-caprae que foram monitoradas na Ilha de Santa Catarina no período de 1996 a 1997, quatro mostraram declínio populacional, quatro estabilidade e duas aumento. Das quatro praias onde a espécie reduziu sua abundância, em três houve expressiva destruição de hábitats durante os eventos erosivos (T.T. Castellani, dados não publicados).

Estudos da fenologia reprodutiva de Ipomoea pes-caprae mostram, para o sul do Brasil, que o período de maior produção de flores e frutos ocorre sob temperaturas e precipitação elevadas (Santos \& Arruda 1995). Na Costa Rica, Wilson (1977) constatou maior produção de flores em períodos chuvosos. Os dados apresentados por Santos \& Arruda (1995), para três ciclos reprodutivos de Ipomoea pes-caprae, sugerem a ocorrência de variações anuais na intensidade de frutificação desta espécie.

Na Ilha de Santa Catarina, Ipomoea pes-caprae ocorre em praias de tamanho, origem e dinamismo geomorfológico distintos, ocupando desde pequenas faixas de pós-praia até amplos trechos de duna frontal. Populações mais abundantes ocorrem em praias do setor sul, leste e norte, de maior energia. A ocorrência e a abundância de Ipomoea pes-caprae é menor no setor oeste da ilha, de menor energia, caracterizado por numerosas praias de pequenas dimensões (T.T. Castellani, dados não publicados).

Considerando-se a variedade de praias colonizadas por Ipomoea pes-caprae na Ilha de Santa Catarina e as diferenças de abundância e de variação populacional no período de 1996 a 1997, este trabalho teve como objetivos: avaliar se ocorrem diferenças espaciais e temporais na proporção de ramos reprodutivos e produção de sementes nestas populações, verificar se as diferenças no vigor reprodutivo podem ser explicadas pelas características das praias e relacionar o quanto as variações anuais podem ser explicadas pelas mudanças populacionais ocorridas ou pelas variações climáticas ou de esforço reprodutivo distinto entre ciclos reprodutivos subsequentes.

\section{Material e métodos}

Espécie em estudo - Ipomoea pes-caprae (L.) R. Br. (Convolvulaceae) é uma espécie perene, estolonífera, que ocorre no pós-praia e na duna frontal em regiões tropicais e temperadas quentes (Hueck 1955, Devall et al. 1991; Devall 1992), tendo sua distribuição mais austral no Atlântico em Santa Catarina (Reitz 1961).

Ipomoea pes-caprae apresenta um sistema aéreo composto por ramos longos e curtos, que também podem ramificar-se (Hueck 1955). As inflorescências desenvolvem-se nos dois tipos de ramos e a produção de sementes é numerosa (Hueck 1955). A espécie apresenta um sistema de reprodução autoincompatível do tipo esporofítico, genético e homomórfico (Devall \& Thien 1992). No sul do Brasil, sua floração e frutificação ocorrem nos meses de verão e outono, em períodos de temperaturas e pluviosidade altas (Santos \& Arruda 1995). Ocorre tendência de perda foliar após a reprodução (Hueck 1955), o que coincide com o período de inverno no sul do Brasil. No verão e outono 
ocorrem a expansão e produção de ramos e aumento no número de folhas (T.T. Castellani, dados não publicados).

Áreas de estudo - Dez praias da Ilha de Santa Catarina (272' - 2752' S; 48⒉' - 48³5' W) foram estudadas: uma no setor oeste, onde Ipomoea pes-caprae ocorre com menor freqüência; quatro no norte, quatro no leste e uma no sul, onde há poucas praias arenosas. As praias variaram de pequenas praias de bolso (Suguio 1992) a extensas faixas adjacentes a campos de dunas (Fig. 1; Tab. 1), permitindo diferentes tamanhos de manchas de Ipomoea pes-caprae.

Em cada praia, três manchas de Ipomoea pescaprae foram marcadas para estudo, considerando-se como manchas, áreas ocupadas pela espécie, descontínuas entre si. A determinação das manchas foi aleatória, sorteando-se três distâncias ao longo de cada praia.

De 1996 a 1997, as praias estudadas sofreram erosão no outono-inverno, com menor alteração de hábitat na Praia da Caieira da Barra do Sul, setor oeste da ilha. No setor norte, houve destruição da barra arenosa que sustentava uma mancha de Ipomoea pescaprae na Praia da Daniela, ocorreram mudanças rápidas e acentuadas de deposição e erosão na Praia do Forte e houve invasão do mar (“overwash”) na duna frontal da Praia da Lagoinha. Em todas as praias dos setores leste e sul houve formação de escarpas na duna frontal. Na Praia da Joaquina, a duna embrionária foi removida, e na Armação, o pós-praia foi intensamente erodido. Perturbação antrópica por corte e queima ocorreu em uma das áreas da Praia da Lagoinha. Em Jurerê, a remoção de uma embarcação encalhada gerou alteração da topografia da duna frontal e redução da cobertura vegetal em uma das manchas (T.T. Castellani, dados não publicados).

Condições climáticas - A Ilha de Santa Catarina possui um clima mesotérmico úmido, tipo Cfa de Köppen, com verões quentes e chuvas bem distribuídas ao longo do ano (Caruso 1990). A temperatura média mensal é de $21{ }^{\circ} \mathrm{C}$, variando de $16{ }^{\circ} \mathrm{C}$ em julho a $25{ }^{\circ} \mathrm{C}$ em fevereiro. A média pluviométrica anual é $1.700 \mathrm{~mm}$, com maiores índices em janeiro e fevereiro e menores índices de junho a agosto (Fig. 2A).

O ano de 1996 foi de menor pluviosidade (1.757,8 mm) que 1997 (2.157,5 mm), ocorrendo déficits hídricos em maio e novembro/1996. As médias de temperatura mensal variaram de $25^{\circ} \mathrm{C}$, nos meses de janeiro e fevereiro, a $14{ }^{\circ} \mathrm{C}$ em agosto/1996 e $18^{\circ} \mathrm{C}$ em julho/1997 (Fig. 2B). De janeiro a maio, período que engloba a maior intensidade reprodutiva de Ipomoea pes-caprae (Santos \& Arruda 1995), as temperaturas e pluviosidade mensais, em média, diferiram pouco $\left(23,36{ }^{\circ} \mathrm{C}\right.$ e $192 \mathrm{~mm}$ para 1996; 23,18 ${ }^{\circ} \mathrm{C}$ e $220 \mathrm{~mm}$ para 1997). A distribuição de chuvas, no entanto, foi distinta, com índice muito alto em janeiro/1997 (640 mm) e déficit hídrico em maio/1996 quando a pluviosidade reduziu a 22,4 mm.

Variação do número de ramos nas manchas - A praia e a duna embrionária são hábitats transitórios, sujeitos à destruição pelas marés altas ou à expansão em períodos favoráveis de deposição. Desta forma, parte do hábitat colonizado por Ipomoea pes-caprae não é

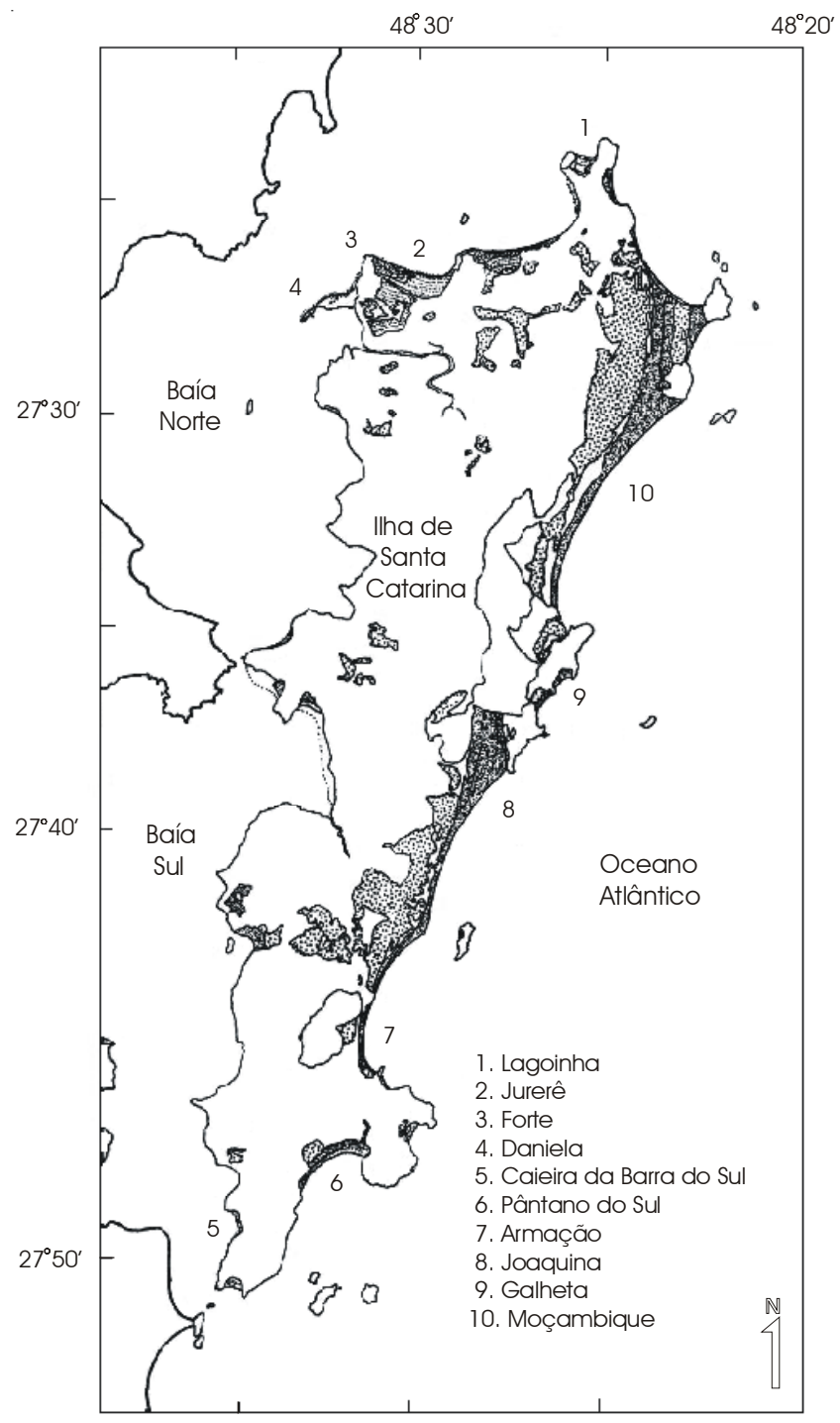

Figura 1. Mapa da Ilha de Santa Catarina situando as 10 praias estudadas e os depósitos costeiros adjacentes, segundo mapa de Caruso Jr. (1993). Linha de costa delimitada com aterros (......) foram ajustadas pelo mapa IPUF (1998). 
Tabela 1. Caracterização e localização das praias estudadas na Ilha de Santa Catarina, SC, Brasil. Dados referentes à localização e dimensões das praias foram obtidos em N.O. Horn Filho (dados não publicados). Os dados de morfologia e entornos foram obtidos em Almeida et al. (1991), Caruso Jr. (1993), Abreu de Castilhos \& Gré (1997), Gré et al. (1997) e N.O. Horn Filho (dados não publicados). As localidades ora designadas como Jurerê, Forte, Daniela e Pântano do Sul representam um sistema de duas praias geográficas, mas compõem uma única faixa arenosa contínua. C - comprimento da praia (m).

\begin{tabular}{|c|c|c|c|c|}
\hline Setores/Praias & Latitude & Longitude & Morfologia e entornos & $\mathrm{C}$ \\
\hline \multicolumn{5}{|l|}{ Norte } \\
\hline Lagoinha & $27^{\circ} 23 ’ 49,0^{\prime \prime}$ & $48^{\circ} 25^{\prime} 27,9^{\prime \prime}$ & Adjacente a cordão holocênico & 920 \\
\hline Jurerê (Jurerê - Jurerê Internacional) & $27^{\circ} 26^{\prime} 14,3^{\prime \prime}$ & $48^{\circ} 29^{\prime} 14,3^{\prime \prime}$ & $\begin{array}{l}\text { Adjacente a planície quaternária de progradação } \\
\text { de cristas praiais }\end{array}$ & 3.200 \\
\hline Forte (Forte - Forte Sul) & $27^{\circ} 26^{\prime} 00,4^{\prime \prime}$ & $48^{\circ} 31^{\prime} 09,8^{\prime \prime}$ & Faixa recente junto a encosta & 855 \\
\hline Daniela (Daniela - Pontal) & $27^{\circ} 26^{\prime} 46,4^{\prime \prime}$ & $48^{\circ} 31^{\prime} 57,9 ”$ & Adjacente a esporão arenoso & 3.000 \\
\hline \multicolumn{5}{|l|}{ Oeste } \\
\hline Caieira da Barra do Sul & $27^{\circ} 48^{\prime} 46,0^{\prime \prime}$ & $48^{\circ} 33^{\prime} 30,5^{\prime \prime}$ & Praia de bolso & 214 \\
\hline \multicolumn{5}{|l|}{ Sul } \\
\hline Pântano do Sul (Pântano do Sul - Açores) & $27^{\circ} 46^{\prime} 49,3^{\prime \prime}$ & 4830’47,7”' & $\begin{array}{l}\text { Adjacente a planície costeira, com cordão inter- } \\
\text { no pleistocênico e externo holocênico e expressi- } \\
\text { vo lençol de dunas }\end{array}$ & 3.900 \\
\hline \multicolumn{5}{|c|}{ (1) } \\
\hline Armação & $27^{\circ} 44^{\prime} 17,3^{\prime \prime}$ & $48^{\circ} 30^{\prime} 27,4^{\prime \prime}$ & $\begin{array}{l}\text { Praia em espiral, adjacente a planície costeira, } \\
\text { com cordão interno pleistocênico e externo holo- } \\
\text { cênico }\end{array}$ & 3.000 \\
\hline Joaquina & $27^{\circ} 37^{\prime} 44,7^{\prime}$ & $48^{\circ} 26^{\prime} 54,6^{\prime}$ & $\begin{array}{l}\text { Adjacente a extensa planície arenosa, com cordão } \\
\text { interno pleistocênico e externo holocênico e campo } \\
\text { de dunas móveis }\end{array}$ & 3.000 \\
\hline Galheta & $27^{\circ} 35^{\prime} 30,3^{\prime \prime}$ & $48^{\circ} 25^{\prime} 29,3^{\prime \prime}$ & Praia de bolso & 1.080 \\
\hline Moçambique & $27^{\circ} 31^{\prime} 21,5^{\prime \prime}$ & $48^{\circ} 25^{\prime} 01,6^{\prime \prime}$ & $\begin{array}{l}\text { Adjacente a extensa planície arenosa, com cordão } \\
\text { interno pleistocênico e externo holocênico e campo } \\
\text { de dunas móveis }\end{array}$ & 11.250 \\
\hline
\end{tabular}

permanente ao longo do tempo e estas variações de hábitat podem permitir a expansão ou retração da população, em relação aos setores de pós-praia e duna ocupados (Fig. 3).

Com base nestas características do hábitat, a avaliação da variação anual da abundância de ramos em manchas de Ipomoea pes-caprae foi feita com transecções permanentes, que permitiram verificar as mudanças na expansão e regressão das manchas e as mudanças em suas densidades. Em cada mancha foi estabelecida uma transecção perpendicular ao mar (do interior de duna à praia), com 1 m larg. e com extensão definida pelo início e o fim da ocorrência de ramos de Ipomoea pes-caprae. A cada amostragem, a extensão da mancha era medida e eram contados todos os ramos longos e curtos presentes na transecção. Para auxiliar na contagem, a transecção foi subdividida em quadrados de $1 \times 1 \mathrm{~m}$. Apesar de terem sido feitas seis amostragens (janeiro, março, maio, agosto e dezembro/1996 e abril/1997), para apresentarmos a variação anual ocorrida, apenas os dados de março/1996 e abril/1997 foram empregados.
Para cada data obteve-se: o total de ramos por mancha (total por transecção), o comprimento da mancha, sua densidade (ramos $/ \mathrm{m}^{2}$ ) e a variação líquida anual de cada parâmetro, expressas pelas diferenças dos valores obtidos em abril/1997 e março/1996.

As tendências de variação populacional (aumento, redução e estabilidade) foram avaliadas para cada praia, considerando-se o total de ramos presentes nas três manchas. Para verificar se as tendências de aumento, redução e estabilidade eram estatisticamente significativas, foram empregados testes de $\mathrm{X}^{2}$ (Zar 1999). Nestes testes avaliou-se o quanto o número de ramos presentes nas transecções em março/1996 e abril/1997 diferiam de uma proporção de 1:1 (estabilidade), sendo os cálculos realizados com correção de Yates no aplicativo BioEstat 2.0 (Ayres et al. 2000).

Variação da ocorrência de reprodução nas manchas A cada amostragem, avaliou-se o número de ramos em reprodução e, em cada ramo, contaram-se as estruturas reprodutivas e suas fenofases: botão floral, flor em antese, fruto verde (após a murcha floral até o 
desenvolvimento inicial do fruto, ainda envolto pelas sépalas), fruto amadurecendo (com coloração acastanhada e parcialmente envolto pelas sépalas), fruto maduro (cápsula seca, fechada, de coloração marrom), fruto com sementes em dispersão (cápsula aberta, expondo as sementes), fruto com sementes já dispersas e estrutura abortada (cicatriz). Com estes dados avaliou-se o número de manchas que iniciaram floração e maturaram frutos em 1996 e em 1997 e a variação na proporção de ramos reprodutivos entre os anos.

Para avaliar se a proporção de ramos que reproduziu em 1996 e em 1997 era significativamente diferente, foram realizados testes de $\mathrm{X}^{2}$ de contingência (Zar 1999), com base no número de ramos reprodutivos e vegetativos amostrados em março/1996 e abril/ 1997. Os testes foram feitos no BioEstat 2.0 (Ayres et al. 2000) e permitiram concluir se houve aumento,

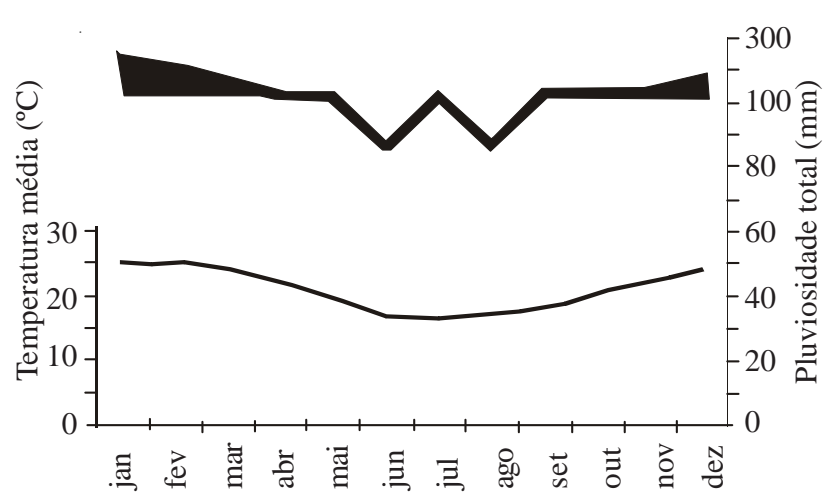

1979-1998

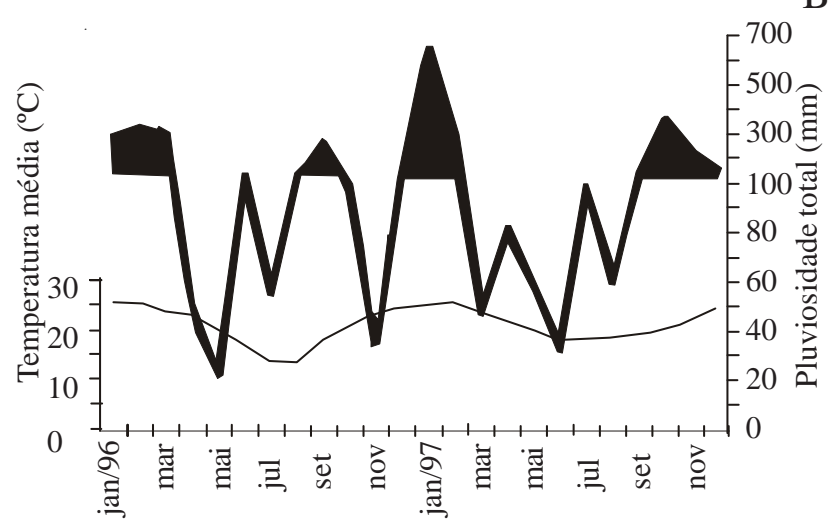

1996-1997

Figura 2. Dados climáticos para a Ilha de Santa Catarina, SC, Brasil. Temperaturas médias (traço mais fino) e pluviosidade (traço mais grosso) mensais para uma série temporal de 20 anos (A) e para os anos de estudo $(\mathrm{B})$, tendo-se período úmido quando $\mathrm{P}>\mathrm{T}$, período super-úmido quando $\mathrm{P}>100 \mathrm{~mm}(\mathbf{\square})$ e déficit hídrico quando $\mathrm{P}<\mathrm{T}$ $(\therefore)$, segundo diagrama climático em Brower \& Zar (1984). Fonte: Destacamento de Proteção ao Vôo de Florianópolis, SC. redução ou constância na proporção de ramos que entraram em reprodução nos dois ciclos subseqüentes.

Variação da produção de frutos e sementes nas manchas - $\mathrm{O}$ total de frutos produzidos nas manchas (total de frutos por transecção) e suas respectivas densidades (frutos $/ \mathrm{m}^{2}$ ) foram obtidos com base no total de frutos amadurecendo a frutos com sementes já dispersas amostrados em maio/1996 e abril/1997. O total de sementes produzidas por mancha foi avaliado pelo número de frutos desenvolvidos x número médio de sementes por fruto. Ipomoea pes-caprae produz até quatro sementes por fruto (Hueck 1955) e, excepcionalmente, até seis (T.T. Castellani, observação pessoal). Para estimar a média de sementes por fruto, 50 frutos maduros foram coletados em cada mancha, porém fora das transecções permanentes. Em algumas áreas, o número de frutos amostrado foi menor que 50, devido à sua escassez.

A variação no total de sementes produzidas por praia em 1996 e 1997 também foi avaliada por testes de $\mathrm{X}^{2}$, similar ao procedimento descrito na análise de abundância de ramos.

Análises de parâmetros correlacionados à intensidade de reprodução - O coeficiente de correlação de Pearson e ajustes de regressão linear simples foram utilizados para avaliar as relações existentes entre os parâmetros reprodutivos (proporção de ramos reprodutivos, densidade de ramos reprodutivos, frutos e sementes) e as características de densidade e comprimento das manchas. Cálculos envolvendo proporções foram feitos com taxas transformadas para arco seno da raiz quadrada da proporção (Sokal \& Rohlf 1979).

\section{Resultados}

Variação do número de ramos nas manchas - De março/1996 a abril/1997, quatro praias mostraram declínio populacional de Ipomoea pes-caprae, ocorrendo redução significativa no número de ramos presentes (Tab. 2). Destas, Joaquina e Daniela mostraram acentuadas reduções no comprimento de todas as manchas, sendo que nesta última, a maior redução decorreu da destruição da barra arenosa no setor sul da praia. Por outro lado, as reduções populacionais observadas na Armação e Lagoinha decorreram, principalmente, do declínio da densidade de ramos nas manchas (Tab. 3).

Em março/1996, o comprimento das manchas de Ipomoea pes-caprae variava de 1 a $50 \mathrm{~m}$, com 
menores extensões na Praia da Caieira da Barra do Sul e maiores na Joaquina. Em um ano, 18 manchas reduziram em extensão, observando-se variação média negativa em seis localidades. Apenas na Praia da Caieira da Barra do Sul todas as manchas expandiram, verificando-se nesta praia as maiores variações médias em comprimento (Tab. 3).

Em março/1996, as manchas de Ipomoea pescaprae tinham cerca de $9,6 \mathrm{ramos} / \mathrm{m}^{2}$, variando de 0,8 a 25,2 ramos/m². Em um ano, 17 manchas reduziram suas densidades, com maiores perdas na Armação e Lagoinha. Na Daniela, todos os ramos foram removidos por erosão no DT3 (Tab. 3).
Na Praia da Caieira da Barra do Sul e em Jurerê houve aumento populacional significativo no número de ramos presentes em 1997 (Tab. 2). Na Praia da Caieira da Barra do Sul este aumento se deu pela expansão das manchas e em Jurerê, pelo adensamento gerado pela regeneração da mancha que havia sofrido perturbação antrópica (Tab. 3).

As demais localidades não mostraram diferenças significativas no total de ramos nas manchas, sendo consideradas como populações estáveis neste período (Tab. 2).

Aspectos fenológicos e ocorrência de floração e frutificação em manchas de Ipomoea pes-caprae -

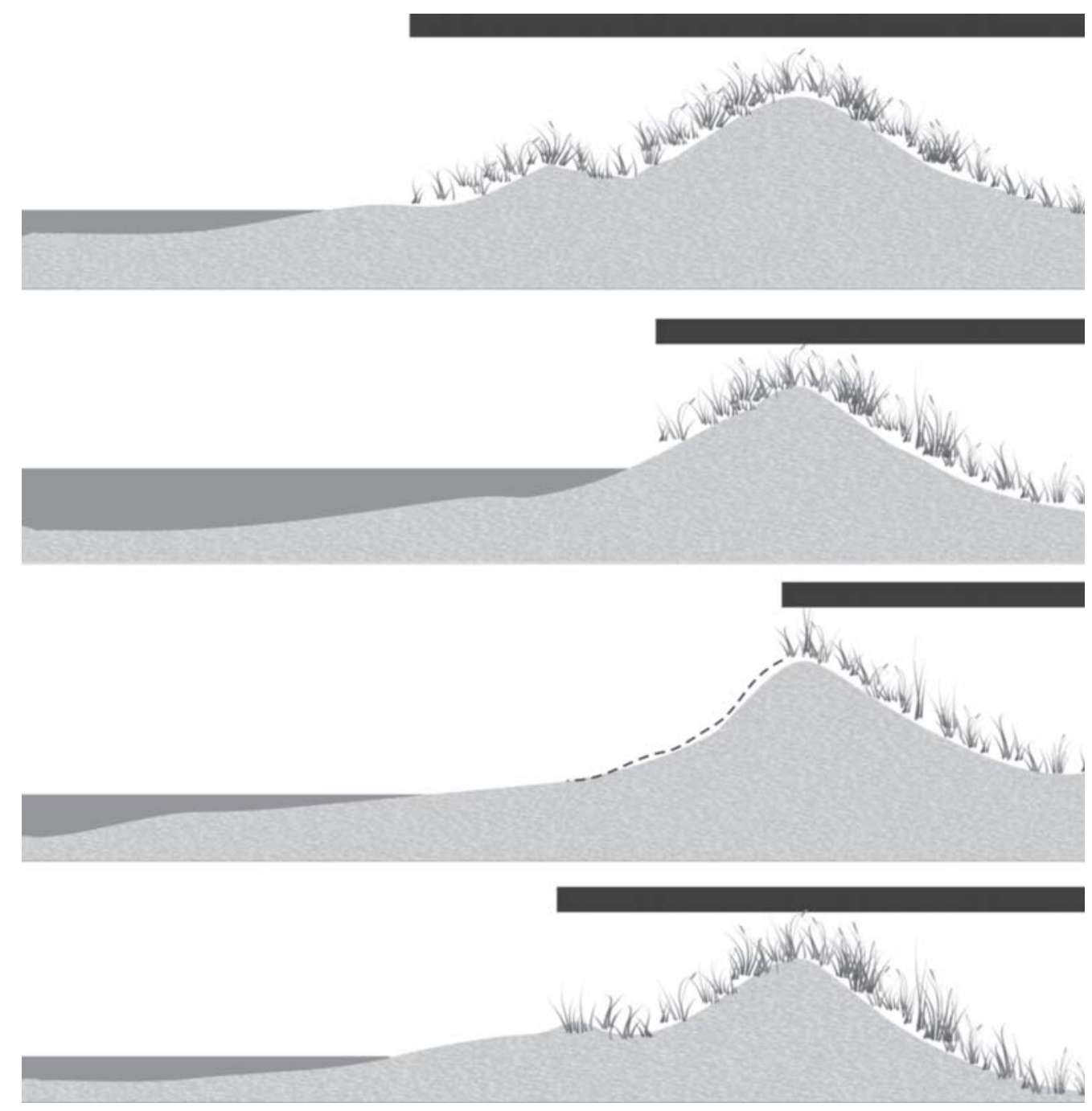

Figura 3. Esquema da morfodinâmica dos setores de pós-praia e duna frontal e variação da vegetação pioneira. A barra preta esquematiza a metodologia empregada na amostragem de manchas de Ipomoea pes-caprae (L.) R. Br. em praias da Ilha de Santa Catarina, SC, Brasil. Em cada mancha, uma transecção permanente com $1 \mathrm{~m}$ larg. foi estabelecida, perpendicular ao mar, tendo sua extensão definida pelo início e o fim da ocorrência de ramos nas manchas. (Esquema adaptado de Hesp 2000). 
Tabela 2. Variação do número de ramos de Ipomoea pes-caprae (L.). R. Br. e proporção de reprodutivos amostrados em março/1996 e abril/1997, em dez praias da Ilha de Santa Catarina, SC, Brasil. Em cada praia, três manchas foram monitoradas com transecções permanentes. Valores de testes de $\mathrm{X}^{2}$ e significância são mostrados. (D) decréscimo, (E) estabilidade e (A) aumento indicam as tendências de variação populacional e de mudanças nas proporções de ramos reprodutivos encontrados.

\begin{tabular}{|c|c|c|c|c|c|c|c|c|c|c|}
\hline & \multicolumn{4}{|c|}{ Ramos por praia } & \multicolumn{2}{|c|}{$\begin{array}{c}\text { Ramos reprodutivos } \\
\text { por praia }\end{array}$} & \multicolumn{4}{|c|}{ Proporção de reprodutivos } \\
\hline & 1996 & 1997 & $X^{2}$ & & 1996 & 1997 & 1996 & 1997 & $\mathrm{X}^{2}$ & \\
\hline Lagoinha & 508 & 375 & $19,7 * * *$ & $\mathrm{D}$ & 219 & 110 & 0,43 & 0,29 & $16,9 * * *$ & $\mathrm{D}$ \\
\hline Jurerê & 103 & 225 & $44,6 * * *$ & A & 40 & 89 & 0,39 & 0,40 & $0,0 \mathrm{~ns}$ & $\mathrm{E}$ \\
\hline Forte & 137 & 151 & $0,6 \mathrm{~ns}$ & $\mathrm{E}$ & 29 & 45 & 0,21 & 0,30 & $2,4 \mathrm{~ns}$ & $\mathrm{E}$ \\
\hline Daniela & 352 & 253 & $15,9 * * *$ & $\mathrm{D}$ & 164 & 88 & 0,47 & 0,35 & $8,0 * *$ & $\mathrm{D}$ \\
\hline Caieira da Barra do Sul & 41 & 95 & $20,6 * * *$ & A & 12 & 2 & 0,29 & 0,02 & $22,9 * * *$ & $\mathrm{D}$ \\
\hline Pântano do Sul & 803 & 763 & $0,97 \mathrm{~ns}$ & $\mathrm{E}$ & 293 & 411 & 0,36 & 0,54 & $47,0 * * *$ & A \\
\hline Armação & 304 & 194 & $23,9 * * *$ & $\mathrm{D}$ & 151 & 40 & 0,50 & 0,21 & $41,1^{* * *}$ & $\mathrm{D}$ \\
\hline Joaquina & 768 & 442 & $87,3 * * *$ & $\mathrm{D}$ & 224 & 86 & 0,29 & 0,19 & $13,4 * * *$ & $\mathrm{D}$ \\
\hline Galheta & 172 & 190 & $0,8 \mathrm{~ns}$ & $\mathrm{E}$ & 55 & 44 & 0,32 & 0,23 & $3,1 \mathrm{~ns}$ & $\mathrm{E}$ \\
\hline Moçambique & 412 & 453 & $1,8 \mathrm{~ns}$ & $\mathrm{E}$ & 207 & 167 & 0,50 & 0,37 & $15,2 * * *$ & $\mathrm{D}$ \\
\hline
\end{tabular}

$\mathrm{ns}=$ valores não significativos $(\mathrm{P}>0,05) ;{ }^{*} \mathrm{p}<0,05 ; * * \mathrm{p}<0,01 ; * * * \mathrm{P}<0,001$

O período de estudo englobou dois ciclos reprodutivos em 25 manchas, ora referidos como ciclo de 1996 e de 1997 (Tab. 4). No primeiro ciclo, botões, flores e frutos verdes ocorreram em janeiro e março, com poucos frutos verdes em maio. Frutos em amadurecimento foram registrados em março e maio. Frutos maduros a já dispersos ocorreram de março a agosto, com poucas manchas ainda reprodutivas neste último mês (Tab. 4). Em dezembro/1996, iniciou-se o novo ciclo reprodutivo, com estruturas em botão, flor e fruto verde, estes em menor freqüência. Frutos maduros da estação anterior persistiam em cinco manchas nesta data. Frutos persistentes também foram observados em janeiro/1996 (Tab. 4).

Ocorreu floração de Ipomoea pes-caprae em todas as praias. O número de manchas que floresceu foi igual nos dois ciclos (27), mas uma das manchas nunca floresceu (FT2) e outras quatro (JT1, DT3, CT3 e GT3) floresceram em apenas um dos ciclos (Tab. 4). No caso da Praia da Daniela, o que de fato ocorreu foi a remoção total de ramos em DT3 pela erosão.

A frutificação foi menos intensa que a floração e o número de manchas que apresentou frutos amadurecendo ou em estágios mais tardios, reduziu de 25 no ciclo de 1996 para 21 em 1997. Quatro manchas nunca amadureceram frutos, duas na Praia do Forte (FT1 e FT2), uma na Caieira da Barra do Sul (CT3) e outra na Galheta (GT3). Em 1997 não ocorreu frutificação na Praia da Caieira da Barra do Sul (Tab. 4).

Variação na proporção de ramos reprodutivos - De março/1996 a abril/1997, a condição mais observada nas praias foi a de redução na proporção de ramos reprodutivos, registrada em seis localidades. Apenas em uma praia ocorreu aumento na intensidade de reprodução e nas três demais não houve mudanças significativas destas proporções (Tab. 2).

Em março/1996, a proporção de ramos reprodutivos nas manchas variava de 0 a 0,88 e em abril/1997 de 0 a 0,59 (Tab. 3). Ao considerarmos o total de ramos amostrados em cada praia, esta proporção variou de 0,21 a 0,50 em 1996 e de 0,02 a 0,54 em 1997 (Tab. 2).

Em todas as praias em que houve declínio populacional de 1996 a 1997 ocorreu menor proporção de ramos reprodutivos em 1997. Nas praias onde houve estabilidade populacional, as tendências foram variadas, porém o mais comum foi não ocorrer alteração significativa na intensidade de reprodução. Nas praias com aumento populacional ocorreu menor proporção de ramos reprodutivos na Caieira da Barra do Sul em 1997 e não houve alteração em Jurerê (Tab. 2).

A proporção de ramos em reprodução não se mostrou relacionada à densidade de ramos nas manchas $(r=0,10 ; \mathrm{P}>0,05)$ no ano de 1996. No entanto, em 1997, as manchas mais densas mostraram maior proporção de ramos reprodutivos (Fig. 4). Por outro lado, não se encontrou qualquer relação entre a proporção de ramos reprodutivos e a extensão das manchas de Ipomoea pes-caprae $(\mathrm{r}=0,003$ e 0,27 ; $\mathrm{P}>0,05$, para 1996 e 1997, respectivamente).

Os dados ora apresentados não mostraram uma correlação significativa entre a proporção de ramos em reprodução em 1997 e a proporção de ramos que 
Tabela 3. Total de ramos de Ipomoea pes-caprae (L.) R. Br. presentes em transecções permanentes (T1, T2 e T3) em março/1996 e abril/1997, em dez praias da Ilha de Santa Catarina, SC, Brasil. O comprimento e a densidade de ramos nas manchas são mostrados, assim como a densidade de ramos reprodutivos e suas respectivas proporções. v - variação líquida observada para cada parâmetro.

\begin{tabular}{|c|c|c|c|c|c|c|c|c|c|c|c|c|c|c|c|}
\hline & \multicolumn{3}{|c|}{$\begin{array}{c}\text { Ramos por } \\
\text { mancha }\end{array}$} & \multicolumn{3}{|c|}{$\begin{array}{l}\text { Comprimento } \\
(\mathrm{m})\end{array}$} & \multicolumn{3}{|c|}{$\operatorname{Ramos} / \mathrm{m}^{2}$} & \multicolumn{3}{|c|}{$\begin{array}{c}\text { Ramos } \\
\text { reprodutivos } / \mathrm{m}^{2}\end{array}$} & \multicolumn{3}{|c|}{$\begin{array}{l}\text { Proporção de } \\
\text { reprodutivos }\end{array}$} \\
\hline & 1996 & 1997 & $\mathrm{v} 1 \mathrm{~s}$ & 1996 & 1997 & $\mathrm{v}$ & 1996 & 1997 & $\mathrm{v}$ & 1996 & 1997 & $\mathrm{v}$ & 1996 & 1997 & $\mathrm{v}$ \\
\hline Lagoinha T1 & 212 & 147 & -65 & 18 & 15 & -3 & 11,8 & 9,8 & $-2,0$ & 5,3 & 2,9 & $-2,4$ & 0,45 & 0,30 & $-0,15$ \\
\hline Lagoinha T2 & 151 & 163 & 12 & 6 & 8 & 2 & 25,2 & 20,4 & $-4,8$ & 11,3 & 5,4 & $-5,9$ & 0,45 & 0,26 & $-0,19$ \\
\hline Lagoinha T3 & 145 & 65 & -80 & 7 & 8 & 1 & 20,7 & 8,1 & $-12,6$ & 7,9 & 2,9 & $-5,0$ & 0,38 & 0,35 & $-0,03$ \\
\hline Jurerê T1 & 39 & 4 & -35 & 18 & 19 & 1 & 2,2 & 0,2 & $-2,0$ & 0,7 & 0,0 & $-0,7$ & 0,33 & 0,00 & $-0,33$ \\
\hline Jurerê T2 & 32 & 37 & 5 & 5 & 4 & -1 & 6,4 & 9,3 & 2,9 & 4,2 & 3,5 & $-0,7$ & 0,66 & 0,38 & $-0,28$ \\
\hline Jurerê T3 & 32 & 184 & 152 & 14 & 13 & -1 & 2,3 & 14,2 & 11,9 & 0,4 & 5,8 & 5,4 & 0,19 & 0,41 & 0,22 \\
\hline Forte T1 & 27 & 34 & 7 & 5 & 4 & -1 & 5,4 & 8,5 & 3,1 & 0,4 & 1,3 & 0,9 & 0,07 & 0,15 & 0,08 \\
\hline Forte T2 & 31 & 44 & 13 & 3 & 3 & 0 & 10,3 & 14,7 & 4,4 & 0,0 & 0,0 & 0,0 & 0,00 & 0,00 & 0 \\
\hline Forte T3 & 79 & 73 & -6 & 10 & 10 & 0 & 7,9 & 7,3 & $-0,6$ & 2,7 & 4,0 & 1,3 & 0,34 & 0,55 & 0,21 \\
\hline Daniela T1 & 114 & 118 & 4 & 16 & 12 & -4 & 7,1 & 9,8 & 2,7 & 3,4 & 5,3 & 1,9 & 0,48 & 0,53 & 0,05 \\
\hline Daniela T2 & 132 & 135 & 3 & 18 & 15 & -3 & 7,3 & 9,0 & 1,7 & 2,1 & 1,7 & $-0,4$ & 0,29 & 0,19 & $-0,1$ \\
\hline Daniela T3 & 106 & 0 & -106 & 7 & 0 & -7 & 15,1 & 0,0 & $-15,1$ & 10,1 & 0,0 & $-10,1$ & 0,67 & - & $-0,67$ \\
\hline Caieira da Barra do Sul T1 & 11 & 17 & 6 & 2 & 4 & 2 & 5,5 & 4,3 & $-1,2$ & 2,5 & 0,0 & $-2,5$ & 0,45 & 0,00 & $-0,45$ \\
\hline Caieira da Barra do Sul T2 & 8 & 22 & 14 & 1 & 4 & 3 & 8,0 & 5,5 & $-2,5$ & 7,0 & 0,5 & $-6,5$ & 0,88 & 0,09 & $-0,79$ \\
\hline Caieira da Barra do Sul T3 & 22 & 56 & 34 & 2 & 6 & 4 & 11,0 & 9,3 & $-1,7$ & 0,0 & 0,0 & 0,0 & 0,00 & 0,00 & 0 \\
\hline Pântano do Sul T1 & 224 & 99 & -125 & 19 & 11 & -8 & 11,8 & 9,0 & $-2,8$ & 1,6 & 2,8 & 1,2 & 0,13 & 0,31 & 0,18 \\
\hline Pântano do Sul T2 & 529 & 631 & 102 & 40 & 39 & -1 & 13,2 & 16,2 & 3,0 & 5,8 & 9,5 & 3,7 & 0,44 & 0,59 & 0,15 \\
\hline Pântano do Sul T3 & 50 & 33 & -17 & 14 & 9 & -5 & 3,6 & 3,7 & 0,1 & 2,2 & 0,9 & $-1,3$ & 0,62 & 0,24 & $-0,38$ \\
\hline Armação T1 & 65 & 47 & -18 & 3 & 5 & 2 & 21,7 & 9,4 & $-12,3$ & 12,7 & 1,6 & $-11,1$ & 0,58 & 0,17 & $-0,41$ \\
\hline Armação T2 & 110 & 46 & -64 & 7 & 5 & -2 & 15,7 & 9,2 & $-6,5$ & 7,6 & 2,4 & $-5,2$ & 0,48 & 0,26 & $-0,22$ \\
\hline Armação T3 & 129 & 101 & -28 & 8 & 10 & 2 & 16,1 & 10,1 & $-6,0$ & 7,5 & 2,0 & $-5,5$ & 0,47 & 0,20 & $-0,27$ \\
\hline Joaquina T1 & 368 & 199 & -169 & 50 & 48 & -2 & 7,4 & 4,1 & $-3,3$ & 1,1 & 0,4 & $-0,7$ & 0,15 & 0,11 & $-0,04$ \\
\hline Joaquina T2 & 381 & 180 & -201 & 33 & $22-$ & -11 & 11,5 & 8,2 & $-3,3$ & 4,8 & 2,3 & $-2,5$ & 0,41 & 0,28 & $-0,13$ \\
\hline Joaquina T3 & 19 & 63 & 44 & 25 & $12-$ & -13 & 0,8 & 5,3 & 4,5 & 0,4 & 1,3 & 0,9 & 0,53 & 0,24 & $-0,29$ \\
\hline Galheta T1 & 58 & 49 & -9 & 14 & 18 & 4 & 4,1 & 2,7 & $-1,4$ & 1,8 & 0,4 & $-1,4$ & 0,43 & 0,16 & $-0,27$ \\
\hline Galheta T2 & 101 & 116 & 15 & 21 & 14 & -7 & 4,8 & 8,3 & 3,5 & 1,4 & 2,5 & 1,1 & 0,30 & 0,30 & 0 \\
\hline Galheta T3 & 13 & 25 & 12 & 5 & 3 & -2 & 2,6 & 8,3 & 5,7 & 0,0 & 0,3 & 0,3 & 0,00 & 0,04 & 0,04 \\
\hline Moçambique T1 & 115 & 75 & -40 & 24 & 23 & -1 & 4,8 & 3,3 & $-1,5$ & 3,3 & 0,3 & $-3,0$ & 0,69 & 0,09 & $-0,6$ \\
\hline Moçambique T2 & 44 & 116 & 72 & 16 & 20 & 4 & 2,8 & 5,8 & 3,0 & 1,6 & 1,4 & $-0,2$ & 0,57 & 0,23 & $-0,34$ \\
\hline Moçambique T3 & 253 & 262 & 9 & 13 & 12 & -1 & 19,5 & 21,8 & 2,3 & 7,9 & 11,1 & 3,2 & 0,41 & 0,51 & 0,1 \\
\hline Média & 120,0 & 104,7 & $-15,3$ & 14,1 & 12,5 & $-1,6$ & 9,6 & 8,6 & $-1,0$ & 3,9 & 2,4 & $-1,5$ & 0,39 & 0,23 & $-0,16$ \\
\hline Erro padrão & 22,7 & 21,6 & 13,2 & 2,1 & 1,9 & 0,8 & 1,2 & 0,9 & 1,0 & 0,7 & 0,7 & 0,7 & 0,04 & 0,31 & 0,05 \\
\hline
\end{tabular}

se reproduziu em $1996(\mathrm{r}=0,28 ; \mathrm{P}>0,05)$. Caso houvesse uma tendência de alternância no vigor reprodutivo em ciclos subseqüentes, seria esperada uma relação negativa entre estas proporções.

Variação na produção de frutos e sementes - Em maio/1996, a maioria das manchas estava com frutos nas fases de amadurecimento a frutos já dispersos (Tab. 4). Nesta data, a densidade média de frutos nas manchas era $9,5 / \mathrm{m}^{2}$, variando de 0 a 30,9 frutos $/ \mathrm{m}^{2}$. A densidade média de sementes produzidas estava em torno de 31,5 sementes $/ \mathrm{m}^{2}$, podendo atingir valores de 112,4 sementes $/ \mathrm{m}^{2}$ em algumas manchas. Em abril/1997, os valores médios estavam mais baixos, cerca de 6,1 frutos $/ \mathrm{m}^{2}$ e 20,9 sementes $/ \mathrm{m}^{2}$. A densidade de frutos variou de 0 a 39,9 frutos $/ \mathrm{m}^{2}$ e a de sementes atingiu valores de 140,5 sementes $/ \mathrm{m}^{2}$ (Tab. 5; Fig. 5).

Em um ano, o total de sementes de Ipomoea pescaprae produzido diminuiu em cinco praias, manteve-se constante em uma e aumentou em quatro (Tab. 6). Das quatro praias que mostraram redução populacional neste período (Tab. 2) todas mostraram menores proporções de ramos reprodutivos e menor produção de sementes (Tab. 6). Por outro lado, na Praia da Caieira da Barra do Sul houve menor produção de sementes (Tab. 6) após aumento populacional do número de ramos (Tab. 2). As populações que se mantiveram estáveis de 1996 a 1997 (Tab. 2) apresentaram ganhos na produção de sementes (Tab. 5). 
Tabela 4. Ocorrência de estruturas reprodutivas em manchas de Ipomoea pes-caprae (L.) R. Br., em diferentes fenofases: 0 - botão ou flor, $\otimes$ - fruto verde, $\bullet$ - fruto amadurecendo, + - maduro, $\square$ - com sementes em dispersão e $\boldsymbol{\Lambda}$ - com sementes já dispersas; A - todas as estruturas estavam abortadas; T1, T2 e T3 - três manchas estudadas.

\begin{tabular}{|c|c|c|c|c|c|c|c|c|c|c|c|c|c|c|c|c|c|c|c|c|c|}
\hline \multirow[b]{3}{*}{ Lagoinha T1 } & \multicolumn{13}{|c|}{ Ciclo1996 } & \multicolumn{8}{|c|}{ Ciclo1997 } \\
\hline & \multicolumn{3}{|c|}{ Jan/1996 } & \multicolumn{4}{|c|}{ Mar/1996 } & \multicolumn{4}{|c|}{ Mai/1996 } & \multicolumn{2}{|c|}{ Ago/1996 } & \multicolumn{3}{|c|}{ Dez/1996 } & \multicolumn{5}{|c|}{ Abr/1997 } \\
\hline & O & $\theta$ & O & $\theta$ & • & + & $\Delta$ & & & $+\square$ & $\Delta$ & + & & O & $\theta$ & + & O & $\theta$ & - & $+\square$ & $\Delta$ \\
\hline Lagoinha T2 & O & $\theta+$ & O & $\theta$ & • & + & $\Delta$ & & $\bullet$ & $+\square$ & $\Delta$ & + & & O & $\theta$ & & O & $\theta$ & - & $+\square$ & $\Delta$ \\
\hline Lagoinha T3 & O & $\theta$ & O & $\theta$ & • & + & $\Delta$ & $\theta$ & $\bullet$ & $+\square$ & $\Delta$ & + & & & & & O & $\theta$ & - & & \\
\hline Jurerê T1 & O & $\theta$ & O & $\theta$ & • & + & $\Delta$ & & & $+\square$ & $\Delta$ & $+\square$ & $\Delta$ & & & & & & & & \\
\hline Jurerê T2 & 0 & $\theta$ & 0 & $\theta$ & - & + & $\Delta$ & & - & $+\square$ & $\Delta$ & $\square$ & $\Delta$ & O & & & O & $\theta$ & - & $+\square$ & $\Delta$ \\
\hline Jurerê T3 & O & $\theta$ & & & $\bullet$ & & $\Delta$ & & & & & & & O & & & 0 & $\theta$ & - & $+\square$ & \\
\hline Forte T1 & & & O & $\theta$ & & & & & & & & & & & & & O & $\theta$ & & & \\
\hline \multicolumn{22}{|l|}{ Forte $\mathrm{T} 2$} \\
\hline Forte T3 & O & $\theta$ & O & $\theta$ & $\bullet$ & + & $\Delta$ & & - & $+\square$ & $\Delta$ & & $\Delta$ & O & $\theta$ & & o & $\theta$ & • & $+\square$ & $\Delta$ \\
\hline Daniela T1 & O & $\otimes$ & 0 & $\theta$ & $\bullet$ & + & $\boldsymbol{\Delta}$ & & $\bullet$ & $+\square$ & $\Delta$ & + & $\Delta$ & O & & + & & $\theta$ & - & $+\square$ & $\Delta$ \\
\hline Daniela T2 & $\mathrm{O}$ & $\theta$ & O & $\theta$ & $\bullet$ & + & $\boldsymbol{\Delta}$ & & & $+\square$ & $\Delta$ & + & $\Delta$ & O & & + & & & & $+\square$ & $\Delta$ \\
\hline Daniela T3 & O & $\theta+$ & & $\theta$ & $\bullet$ & + & $\boldsymbol{\Delta}$ & & $\bullet$ & $+\square$ & $\Delta$ & & & & & & & & & & \\
\hline Caieira da Barra do Sul T1 & 0 & Q & 0 & $\theta$ & $\bullet$ & & & & & & & & & O & & & & & & & \\
\hline Caieira da Barra do Sul T2 & O & $\theta$ & O & $\theta$ & $\bullet$ & & & & & + & $\Delta$ & & $\Delta$ & O & & & & & & & \\
\hline Caieira da Barra do Sul T3 & & & & & & & & & & & & & & O & & & & & & & \\
\hline Pântano do Sul T1 & O & $\theta$ & O & $\theta$ & $\bullet$ & . & $\Delta$ & & & $+\square$ & $\Delta$ & & & & & & & & - & $+\square$ & $\Delta$ \\
\hline Pântano do Sul T2 & O & $\theta$ & O & $\theta$ & $\bullet$ & + & $\Delta$ & $\theta$ & - & $+\square$ & $\Delta$ & + & & O & $\theta$ & & O & $\theta$ & - & $+\square$ & $\Delta$ \\
\hline Pântano do Sul T3 & O & $\theta$ & & $\theta$ & $\bullet$ & + & $\boldsymbol{\Delta}$ & & & $+\square$ & $\Delta$ & & & & & & & & - & $+\square$ & $\Delta$ \\
\hline Armação T1 & 0 & $\theta$ & O & $\theta$ & $\bullet$ & + & $\Delta$ & & $\bullet$ & $+\square$ & $\Delta$ & & & & & & O & $\theta$ & & & \\
\hline Armação T2 & 0 & $\theta$ & 0 & $\theta$ & $\bullet$ & + & & $\theta$ & - & $+\square$ & $\Delta$ & & & & & & 0 & $\theta$ & - & & \\
\hline Armação T3 & O & $\theta$ & 0 & $\theta$ & $\bullet$ & + & & & $\bullet$ & $+\square$ & $\Delta$ & & & & & & 0 & $\theta$ & - & + & \\
\hline Joaquina T1 & 0 & $\theta$ & 0 & $\theta$ & - & + & $\Delta$ & & - & $+\square$ & $\Delta$ & & $\Delta$ & O & $\theta$ & & & & - & $+\square$ & $\Delta$ \\
\hline Joaquina T2 & O & $\theta$ & O & $\theta$ & - & + & $\boldsymbol{\Delta}$ & & - & $+\square$ & $\Delta$ & & $\Delta$ & O & $\theta$ & & & $\theta$ & - & $+\square$ & $\Delta$ \\
\hline Joaquina T3 & O & $\theta$ & 0 & $\theta$ & & & & & & & & & & O & & & & $\theta$ & & $\square$ & 4 \\
\hline Galheta T1 & 0 & $\theta$ & 0 & $\theta$ & • & & & & & & & & & 0 & & & O & & & $+\square$ & \\
\hline Galheta T2 & 0 & $\theta$ & 0 & $\theta$ & & + & & & • & $+\square$ & $\Delta$ & + & & O & $\theta$ & + & 0 & $\theta$ & - & $+\square$ & 4 \\
\hline Galheta T3 & & & & & & & & & & & & & & & & & A & & & & \\
\hline Moçambique T1 & O & $\theta$ & O & $\theta$ & - & + & $\boldsymbol{\Delta}$ & $\theta$ & - & $+\square$ & $\Delta$ & $+\square$ & & O & & + & 0 & $\theta$ & 0 & $+\square$ & 4 \\
\hline Moçambique T2 & 0 & $\theta$ & 0 & $\theta$ & $\bullet$ & + & $\Delta$ & $\theta$ & $\bullet$ & $+\square$ & $\Delta$ & $+\square$ & $\Delta$ & 0 & & & 0 & $\theta$ & - & $+\square$ & 4 \\
\hline Moçambique T3 & O & $\theta$ & 0 & $\theta$ & - & + & $\Delta$ & $\theta$ & - & $+\square$ & $\Delta$ & + & $\Delta$ & O & & & & $\theta$ & - & $+\square$ & 4 \\
\hline
\end{tabular}

*As manchas PST1, PST3 e GT3 não foram amostradas em flor em dezembro/1996 e abril/1997, mas suas florações foram consideradas no segundo ciclo já que mostraram frutos amadurecendo (PST1 e PST3) e inflorescências abortadas em fruto verde (GT3) em abril/1997.

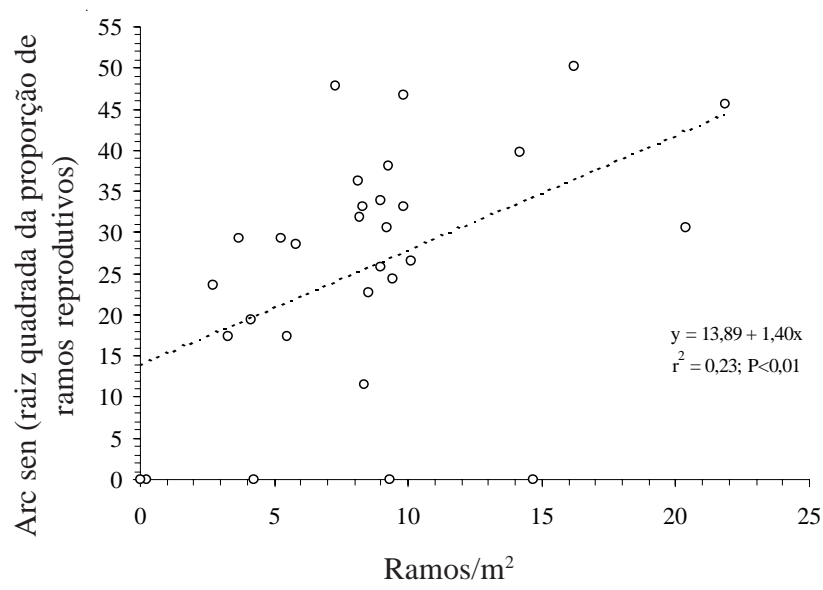

Figura 4. Variação da proporção de ramos reprodutivos de Ipomoea pes-caprae (L.) R. Br. em função da densidade total de ramos presentes nas manchas em abril/1997.
Variação da produção de sementes nos diferentes setores da ilha - Na Ilha de Santa Catarina, as praias com maior abundância de sementes ocorreram nos setores norte, sul e leste da ilha, adjacentes a depósitos costeiros desenvolvidos. Os menores estoques ocorreram na costa oeste, na Praia da Caieira da Barra do Sul, e na Praia do Forte, no norte da ilha. Estas praias são as de menor extensão e menor depósito costeiro associado, dentre as dez praias estudadas (Fig. 1; Tab. 1 e 6).

\section{Discussão}

De forma geral, a tendência mais freqüente observada no período de estudo foi de redução do vigor reprodutivo nas populações de Ipomoea pes-caprae. 
Tabela 5. Densidade de frutos e de sementes em manchas de Ipomoea pes-caprae (L.) R. Br. amostradas em maio/1996 e abril/1997, em 10 praias da Ilha de Santa Catarina, SC, Brasil. Em cada praia, três manchas foram monitoradas com transecções permanentes (T1, T2 e T3).

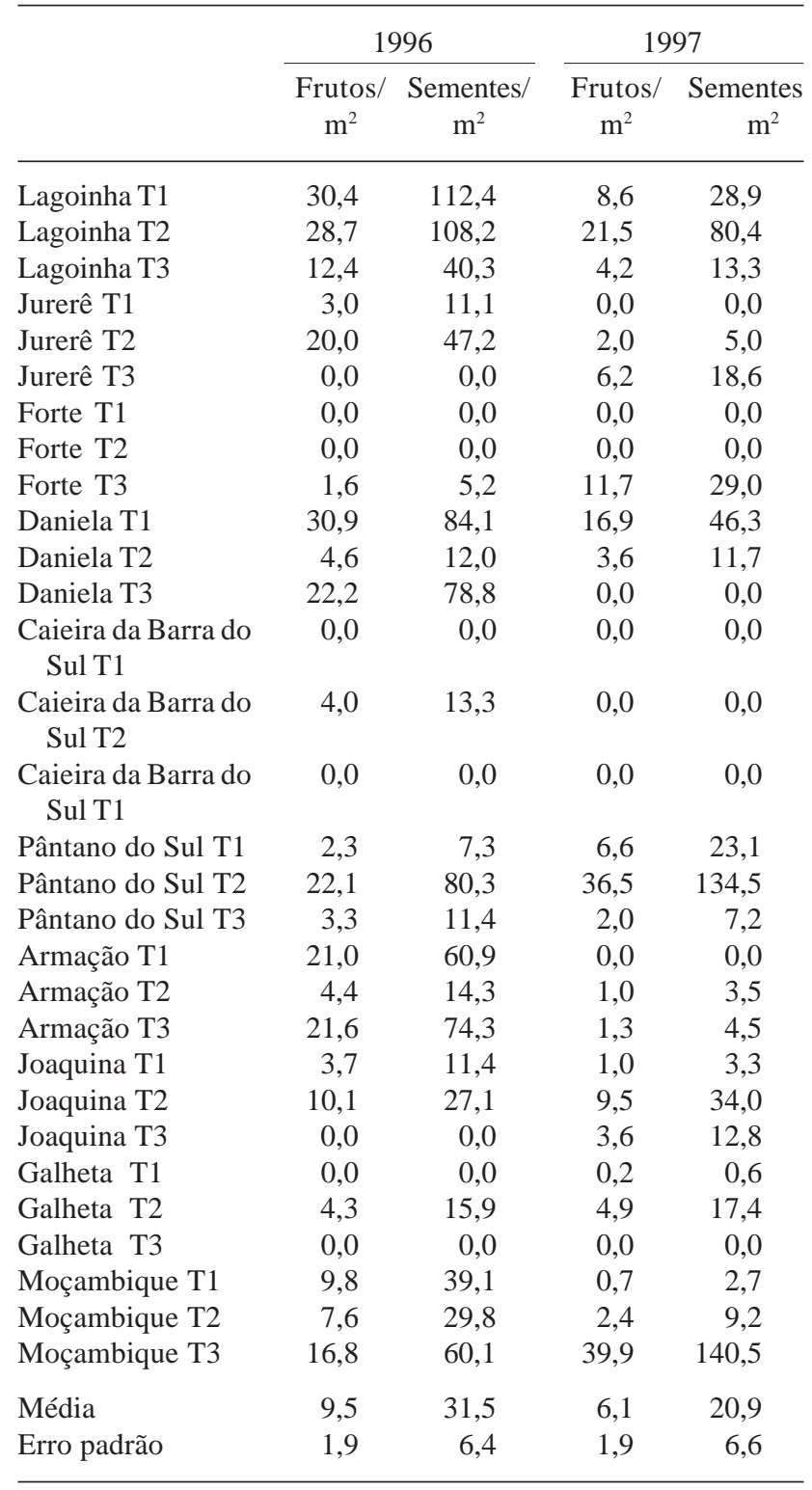

Esta tendência, no entanto, não ocorreu em todas as praias estudadas e algumas destas diferenças podem estar relacionadas às variações populacionais e à intensidade de erosão marinha sofrida no inverno de 1996.

Isto é sugerido, uma vez que todas as populações que mostraram declínios populacionais de 1996 a 1997 reduziram a percentagem de ramos reprodutivos e a produção de sementes. Nestas praias ocorreu acentuada destruição de hábitat, como descrito para as praias da Armação, Joaquina e Daniela (Castellani
2003), o que reduziu a expansão e densidade das manchas. A ação de invasão marinha (“overwash”) ocorrida na Lagoinha pode também ter afetado a densidade de ramos. Apesar de espécies de duna serem tolerantes à salinidade e à certos graus de soterramento, as ações invasivas do mar removem, soterram e danificam os ramos destas espécies e aumentam a salinidade no solo (Lee \& Ignaciuk 1985; Sykes \& Wilson 1990; Hesp 1991; Maun 1998). Na ação erosiva ocorrida em setores destas praias, também o hábitat disponível para a recolonização ficou mais limitado.

Por outro lado, como explicar a redução do vigor reprodutivo na Praia da Caieira da Barra do Sul onde houve aumento populacional? Sugere-se que este declínio esteja associado à expansão dos estolões, mais propriamente, à presença de ramos mais novos. Segundo Noble et al. (1979) e Costa et al. (1991), baixa proporção de ramos reprodutivos é esperada em clones jovens ou em populações em fase invasora. Padrão similar é sugerido para Ipomoea pes-caprae em praias em progressão, onde há menor abundância de estolões floridos devido à idade mais jovem dos indivíduos e à grande produção de estolões (Devall et al. 1991; Devall 1992). A Praia da Caieira da Barra do Sul não é uma praia em progressão. No entanto, esta praia, situada em setor de menor dinamismo costeiro (Cruz 1998), foi pouco afetada pela erosão de 1996, com expansão populacional durante o verão de 1997 (T.T. Castellani, dados não publicados).

Padrão distinto, no entanto, ocorreu na Praia de Jurerê, onde houve aumento populacional, mas não ocorreu redução do vigor reprodutivo. Sabe-se que o aumento em Jurerê derivou da regeneração de uma mancha que sofreu perturbação antrópica em maio/1996 e que o aumento populacional decorreu de seu adensamento. O período no qual ocorreram a perturbação e o brotamento talvez possa explicar estas diferenças. T.T. Castellani (dados não publicados) descreveu as variações sazonais ocorridas nestas áreas e mostrou que o aumento da densidade de ramos em Jurerê se deu no período de maio a dezembro. $\mathrm{Na}$ Caieira da Barra do Sul, a expansão da mancha deu-se de dezembro a abril. Desta forma, no período reprodutivo, os ramos em Jurerê mostravam mais tempo de desenvolvimento, o que poderia explicar parte das diferenças encontradas.

No ciclo reprodutivo de 1997, foi encontrada maior proporção de ramos reprodutivos de Ipomoea pescaprae nas manchas mais densas. Cordazzo \& Seeliger (2003) relataram que estes incrementos são 

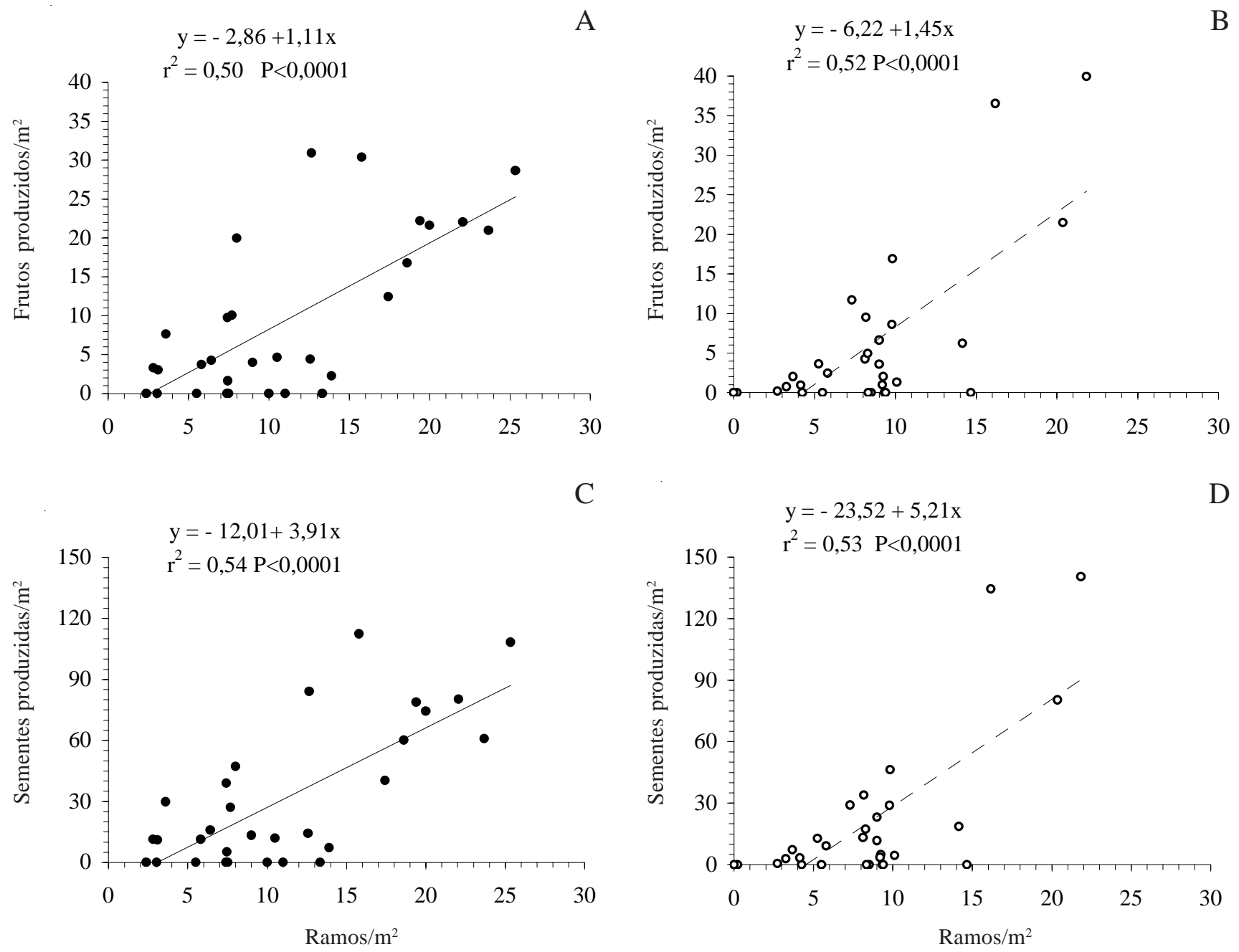

Figura 5. Variação da densidade de frutos e de sementes de Ipomoea pes-caprae (L.) R. Br., em função da densidade de ramos presentes nas manchas em maio/1996 (A, C) e em abril/1997 (B, D).

Tabela 6. Variação do número de sementes de Ipomoea pes-caprae (L.) R. Br. produzidas em maio/1996 e abril/1997, em 10 praias da Ilha de Santa Catarina, SC, Brasil. Em cada praia, três manchas foram monitoradas com transecções permanentes. Valores de testes de $\mathrm{X}^{2}$ e significância são mostrados. (D) decréscimo, (E) estabilidade e (A) aumento indicam as tendências de variação na produção de sementes.

\begin{tabular}{|c|c|c|c|}
\hline & 1996 & 1997 & $\mathrm{X}^{2}$ \\
\hline Lagoinha & 1.661 & 1.182 & $80,4 * * * \mathrm{D}$ \\
\hline Jurerê & 282 & 261 & $0,7 \mathrm{~ns} \quad \mathrm{E}$ \\
\hline Forte & 25 & 290 & $221,3 * * * \mathrm{~A}$ \\
\hline Daniela & 1.351 & 731 & $184,0 * * * \mathrm{D}$ \\
\hline Caieira da Barra do Sul & 23 & 0 & $21,0 * * * \mathrm{D}$ \\
\hline Pântano do Sul & 1.757 & 5.562 & $1.978,1 * * * \mathrm{~A}$ \\
\hline Armação & 202 & 63 & $71,9 * * * \mathrm{D}$ \\
\hline Joaquina & 1.158 & 1.059 & $4,3 * \quad \mathrm{D}$ \\
\hline Galheta & 67 & 255 & $108,6 * * * \mathrm{~A}$ \\
\hline Moçambique & 1.370 & 1.932 & $96,2 * * * \mathrm{~A}$ \\
\hline
\end{tabular}

$\mathrm{ns}=$ valores não significativos $(\mathrm{P}>0,05) ;{ }^{*} \mathrm{p}<0,05 ; * * * \mathrm{P}<0,001$ esperados para áreas de maior estabilidade. No presente estudo, esta relação poderia sugerir que as manchas que permaneceram ou restabeleceram maiores densidades de ramos após os eventos erosivos de 1996 evidenciaram maior vigor reprodutivo.

Neste estudo, as variações na percentagem de ramos reprodutivos de Ipomoea pes-caprae entre os anos subseqüentes não mostrou tendência que sugira um caráter cíclico na alocação de recursos para a reprodução. Não houve evidências de que ciclos com maior proporção de ramos reprodutivos sejam seguidos por ciclos com menor proporção e vice-versa, por vezes sugerido para explicar variações anuais de esforço reprodutivo (Harper 1977).

No que diz respeito às condições climáticas e às variações de reprodução nas populações estudadas, observou-se que os períodos de verão-outono de 1996 e 1997 mostraram diferenças na distribuição das chuvas 
e não no total de precipitação. A interferência desta variação é difícil de ser avaliada devido às diferentes mudanças populacionais ocorridas nas praias. No entanto, se considerarmos as quatro populações que se mantiveram estáveis de 1996 a 1997, todas mostraram aumento na produção de sementes. Isto poderia sugerir melhores condições climáticas em 1997 no que se refere à maturação de sementes, já que déficits hídricos, como o ocorrido em maio/1996, podem ser um fator que limita a produção de sementes nas dunas (Sterk et al. 1982; De Jong \& Klinkhamer 1988; Klinkhamer et al. 1988; Cordazzo 1998).

O presente estudo realizou uma avaliação das populações de Ipomoea pes-caprae na Ilha de Santa Catarina, pois estas populações devem ser vistas de forma mais integrada, devido aos constantes riscos de destruição e reconstrução de seus hábitats, que podem gerar ciclos de remoção e recolonização populacional. Neste processo de recolonização, a dispersão marinha garante a colonização de novas áreas (Lee \& Ignaciuk 1985; Maun 1985), tendo as sementes de Ipomoea pes-caprae capacidade de se manterem viáveis por pelo menos seis meses no mar (Guppy 1917 apud Devall \& Thien 1989).

O período de frutificação de Ipomoea pes-caprae ocorre no outono, estando a maioria das sementes já dispersas no inverno. No outono e principalmente no inverno há maior ocorrência de eventos erosivos (Cruz 1998). Estes eventos podem remover manchas inteiras de Ipomoea pes-caprae, como ocorrido na Praia da Daniela, e lançar ao mar grande quantidade de sementes. Os maiores estoques de sementes de Ipomoea pes-caprae na Ilha de Santa Catarina estão em praias que são adjacentes a depósitos costeiros mais desenvolvidos. Estas praias podem representar fonte de sementes para as praias menores, como a Caieira da Barra do Sul e o Forte, com menor intensidade de floração e frutificação. Obeso \& Aedo (1992) sugeriram que as áreas da praia e da planície costeira adjacente podem determinar áreas-fonte (planícies grandes) e receptoras de sementes (planícies pequenas) em vegetação de duna em ilhas.

Geograficamente, a Praia da Daniela representa a última população de Ipomoea pes-caprae bem estabelecida na costa norte, em direção ao oeste da Ilha de Santa Catarina. No setor oeste, as populações de Ipomoea pes-caprae são raras e a da Caieira da Barra do Sul, que não produziu sementes, é a melhor estabelecida (T.T. Castellani, dados não publicados). A Praia da Daniela poderia representar uma fonte de sementes para esse setor, mas dificilmente suas sementes chegarão às pequenas praias do sudoeste da ilha, devido ao padrão de circulação de correntes das baías norte e sul (M.G. Nunes, dados não publicados). As principais fontes de sementes para essa região devem ser praias do sul da ilha ou do continente.

As diferenças entre manchas de Ipomoea pescaprae podem definir, inclusive, setores-fonte e receptores de sementes, numa mesma praia. $\mathrm{Na}$ Daniela, por exemplo, ocorreu remoção de população no setor sul. O setor norte, mais estável, poderia fornecer sementes para este setor, sendo dispersas pelas correntes de deriva norte-sul (Almeida et al. 1991) garantindo, assim, a recolonização local.

Ipomoea pes-caprae é referida como espécie produtora de grande quantidade de sementes, estimando-se de 400 a 500 flores e de 1.000 a 2.000 sementes por planta adulta, no litoral de São Paulo (Hueck 1955). Wilson (1977) mencionou uma elevada produção de sementes em praias da Costa Rica, mas não fez qualquer estimativa. Devall (1987) referiu-se a médias máximas de 9 frutos $/ \mathrm{m}^{2}$ em Grand Isle, Lousiana, e de 3,5 frutos $/ \mathrm{m}^{2}$ em praias ao longo do Golfo do México (Devall \& Thien 1989). Santos \& Arruda (1995) estimaram uma produção máxima de 20 a 80 frutos/ $\mathrm{m}^{2} /$ quinzena, em três anos de estudo na Praia da Joaquina, Ilha de Santa Catarina. Os dados do presente trabalho não são comparáveis aos de Hueck (1955), que fez estimativas com base em indivíduos. Em relação à costa norte americana, os valores médios ora obtidos por mancha de Ipomoea pes-caprae ficaram entre 9,5 e 6,1 frutos $/ \mathrm{m}^{2}$, não sendo muito diferentes dos observados no Atlântico norte.

Por outro lado, os valores estimados para a Praia da Joaquina por Santos \& Arruda (1995) foram superiores aos aqui obtidos para as manchas de Ipomoea pes-caprae nesta praia $\left(10\right.$ frutos $\left./ \mathrm{m}^{2}\right)$ ou nas demais praias estudadas (no máximo 40 frutos $/ \mathrm{m}^{2}$ ). Tais diferenças podem decorrer das distintas metodologias empregadas, das áreas amostradas, das diferenças de vigor e idade de manchas ou reforçar a tendência de redução dessas populações, em função dos ciclos erosivos que ocorreram nos anos de 1990.

\section{Referências bibliográficas}

Abreu de Castilhos, J. \& Gré, J.C.R. 1997. Praias da Ilha de Santa Catarina: caracterização morfológica e problemas de erosão costeira. Pp. 107-113. In: Colóquio Francobrasileiro sobre manejo costeiro da Ilha de Santa Catarina. Florianópolis 1997. Florianópolis, UFSCUniversité Bordeaux 1. 
Almeida, E.A.; Castilhos, J.A.; Simon, A.A.; Ávila, E.L.; Aumond, J.J.; Pinto, M.L.C.; Dal Santo, M.A. \& Infante Jr., N. 1991. Observações geomorfológicas na praia do Forte - Ilha de Santa Catarina, município de Florianópolis, SC. Geosul 6(11): 38-54.

Ayres, M.; Ayres Jr., M.; Ayres, D.L. \& Santos, A.S. 2000. BioEstat 2.0 - Aplicações estatísticas nas áreas das ciências biológicas e médicas. Belém, Sociedade Civil Mamirauá/MCT-CNPq.

Brower, J.E. \& Zar, J.H. 1984. Field \& laboratory methods for general ecology. Dubuque, Wm. C. Brown Publishers.

Caruso, M.M.L. 1990. O desmatamento da Ilha de Santa Catarina de 1500 aos dias atuais. Florianópolis, Editora da UFSC.

Caruso Jr., F. 1993. Mapa geológico da Ilha de Santa Catarina: texto explicativo e mapa. Notas Técnicas 6: 1-28.

Cordazzo, C.V. 1998. Biologia de Senecio crassiflorus (Poir) DC. nas dunas costeiras no sul do Brasil. I. Características reprodutivas. Pp. 92-96. In: Anais do IV Simpósio de ecossistemas brasileiros. Águas de Lindóia 1998. São Paulo, ACIESP, v.3.

Cordazzo, C.V. \& Seeliger, U. 2003. Reproduction and vegetative regeneration in Blutaparon portulacoides (Amaranthaceae) on backshores in southern Brazil. Journal of Coastal Research 35: 481-485.

Costa, C.S.B.; Seeliger, U. \& Cordazzo, C.V. 1991. Leaf demography and decline of Panicum racemosum populations in coastal foredunes of southern Brazil. Canadian Journal of Botany 69: 1593-1599.

Cruz, O. 1998. A Ilha de Santa Catarina e o continente próximo. Florianópolis, Editora da UFSC.

De Jong, T.J. \& Klinkhamer, P.G.L. 1988. Population ecology of the biennials Cirsium vulgare and Cynoglossum officinale in a Coastal sand-dune area. Journal of Ecology 76: 366-382.

Devall, M.S. 1987. Ecology of Ipomoea pes-caprae (Convolvulaceae) at Grand Isle, Louisiana. Proceedings of Louisiana Academy of Sciences 50: 7-12.

Devall, M.S. 1992. The Biological flora of coastal dunes and wetlands. 2. Ipomoea pes-caprae (L.) Roth. Journal of Coastal Research 8(2): 442-456.

Devall, M.S. \& Thien, L.B. 1989. Factors influencing the reproductive success of Ipomoea pes-caprae (Convolvulaceae) around the Gulf of Mexico. American Journal of Botany 76(12): 1821-1831.

Devall, M.S. \& Thien, L.B. 1992. Self-incompatibility in Ipomoea pes-caprae (Convolvulaceae). American Midland Naturalist 128(1): 22-29.

Devall, M.S.; Thien, L.B. \& Platt, W.J. 1991. The ecology of Ipomoea pes-caprae, a pantropical strand plant. Pp. 231-249. In: Proceedings of the Symposium on coastal sand dunes. Ontario 1990. Ontario, University of Guelph.

Gré, J.C.R.; Abreu de Castilhos, J. \& Horn Filho, N.O. 1997. Depósitos quaternários da praia do Pântano do Sul, Ilha de Santa Catarina, Brasil. Pp. 211-217. In: Colóquio Franco-brasileiro sobre manejo costeiro da Ilha de Santa Catarina. Florianópolis 1997. Florianópolis, UFSCUniversité Bordeaux 1.
Harper, J.L. 1977. Population biology of plants. London, Academic Press.

Hesp, P.A. 1991. Ecological processes and plant adaptations on coastal dunes. Journal of Arid Environments 21: 165-191.

Hesp, P.A. 2000. Coastal sand dunes: form and function. CDVN Technical Bulletin 4: 1-28.

Hueck, K. 1955. Plantas e formação organogênica das dunas no litoral paulista - Parte 1. São Paulo, Instituto de Botânica.

Huiskes, A.H.L. \& Harper, J.L. 1979. The demography of leaves and tillers of Ammophila arenaria in a dune sere. Oecologia Plantarum 14(4): 435-446.

IPUF. 1998. Mapa físico-político do município de Florianópolis (Escala 1:100.000). Florianópolis, Edeme.

Klinkhamer, P.G.; De Jong, T.J. \& Meijden, E. Van Der. 1988. Production, dispersal and predation of seeds in the biennial Cirsium vulgare. Journal of Ecology 76: 403-414.

Leal, P.C.; Horn Filho, N.O. \& Oliveira, J.S. 1998. Evidências erosivas do setor centro-norte da praia de Moçambique, Ilha de Santa Catarina, Santa Catarina, Brasil. Geosul 14(27): 229-231.

Lee, J.A. \& Ignaciuk, R. 1985. The physiological ecology of strandline plants. Vegetatio 62: 319-326.

Little, L.R. \& Maun M.A. 1996. The Ammophila problem revisited: a role for mycorrhizal fungi. Journal of Ecology 84: 1-4.

Mantovani, A. \& Morellato, P. 2000. Fenologia da floração, frutificação, mudança foliar e aspectos da biologia floral do palmiteiro. Pp. 23-38. In: M.S. Reis \& A. Reis (eds.). Euterpe edulis Martius - (Palmiteiro) - Biologia, conservação e manejo. Itajaí, Herbário Barbosa Rodrigues.

Maun, M.A. 1985. Population biology of Ammophila breviligulata and Calamovilfa longifolia on Lake Huron sand dunes. I. Habitat, growth form, reproduction, and establishment. Canadian Journal of Botany 63: 113-124.

Maun, M.A. 1998. Adaptations of plants to burial in coastal sand dunes. Canadian Journal of Botany 76: 713-738.

Noble, J.C.; Bell, A.D. \& Harper, J.L. 1979. The population biology of plants with clonal growth: I. The morphology and structural demography of Carex arenaria. Journal of Ecology 67: 983-1008.

Obeso, J.R. \& Aedo, C. 1992. Plant-species richness and extinction on isolated dunes along the rocky coast of northwestern Spain. Journal of Vegetation Science 3(1): 129-132.

Pfadenhauer, J. 1978. Contribuição ao conhecimento da vegetação e de suas condições de crescimento nas dunas costeiras do Rio Grande do Sul, Brasil. Revista Brasileira de Biologia 38(4): 827-836.

Reitz, R. 1961. Vegetação da zona marítima de Santa Catarina. Sellowia 13: 17-111. 
Santos, C.R. \& Arruda, V.L.V. 1995. Floração, predação de flores e frutificação de Ipomoea pes-caprae e I. imperati (Convolvulaceae). Insula 24: 15-36.

Sokal, R.R. \& Rohlf, F.J. 1979. Biometría - principios y métodos estadísticos en la investigación biológica. Madrid, H. Blume Ediciones.

Sterk, A.A.; Duijkaren, A.; Hogervorst, J. Van. \& Verbeek, E.D.M. 1982. Demographic studies of Anthyllis vulneraria L. in the Netherlands. II. Population density, fluctuations and adaptations to arid conditions, seed populations, seedling mortality, and influence of the biocenosis on demographic features. Acta Botanica Neerlandica 31(1/2): 11-40.
Suguio, K. 1992. Dicionário de geologia marinha. São Paulo, T.A. Queiroz Editora Ltda.

Sykes, M.T. \& Wilson, J.B. 1990. An experimental investigation into the response of New Zealand sand dune species to different depths of burial by sand. Acta Botanica Neerlandica 39(2): 171-181.

Watkinson, A.R. 1997. Plant population dynamics. Pp. 359-400. In: M.J. Crawley (ed.). Plant ecology. Oxford, Blackwell Science.

Wilson, D.E. 1977. Ecological observations on the tropical strand plants Ipomoea pes-caprae (L.) R. Br. (Convolvulaceae) and Canavalia maritima (Aubl.) Thou (Fabaceae). Brenesia 10/11: 31-42.

Zar, J.H. 1999. Biostatistical analysis. Upper Saddle River, Prentice Hall. 